Der Verfasser will dann seinem Vorschlage gemäss, die Zinsen von 20000 Thlr. dem Apotheker als Gehalt oder zwei Drittheile als Pension gewähren. Einige wũrden mit Freuden den Vorschlag annehmen, andere ihn abweisen, wenn er ja einmal, was kaun zu erwarten, zur Ausführung kommen sollte.

Endlich bespricht der Verfasser in einem Anhange den in den Berliner Zeitungen veröffentlichen Aufsatz des Prof. Dr. C. H. Schulz: *über die neue preussische Pharmakopöe und ihre Wirkung auf die Kranken a, welcher Pharmakopōe und. Taxe tadelt, auf die hoheo Preise der Apotheken hinweist, das Gesetz der Selbstanfertigung der Präparate in den Apotheken verwerflich findet, welche letztere Ausstellung allein schon genugsam erweiset, wie wenig der Herr Professor $S$ chulz sich auf den richtigen Standpunct der Beurtheilung gestellt hat, was selbst Laien gefunden haben: denn wer das tadelt, was zum Nutzen der Wissenschaft, also auch der Menschheit angeordnet ist, der bricht damit den Stab über sich selbst. Es ist ganz eigentlich Sache der Verfasser der Pharmakopöe und der Taxe, welche unter Autorität der höchsten Medicinal-Behörde bearbeitet wurden, den Handschuh aufzunehmen, wenn sie nicht, wie so viele Sachverständige, der Ansicht sein sollten, dass es einer Widerlegung gar nicht bedürfen werde!

Sicher ist die Schrift des Hrn. Jonas aus dem besten Willen: wzu nützen, " hervorgegangen; dass aber seine Aufstellung und Beantwortung der von ihm selbst gestellien Fragen eine ganz consequente und richlige sei, dass ferner seine Vorschläge, wenn sie ausführbar wären und ausgeführt werden sollten, zum allgemeinen Heile führen würden, darüber erlaube ich mir noch bescheidene $Z$ weifel zu äussern. Weil ich bereits früher und sogar wiederholt meine Ansichten über Reform des Apothekenwesens ausgesprochen habe, so darf ich hier cine nochmalige Repetition für überflüssig erachten.

\title{
4) Ueber eine wahrscheinliche Selbstentzündung in dem Keller einer Apotheke; mitgetheilt vom Kreisdirector Apotheker Weber in Schwelm.
}

In der Nacht vom 28. auf den 29. October entstand im Keller einer zum Vereinskreise Schwelm gehörenden benachbarten Apotheke gegen 2 Uhr eine Feuersbrunst, welche in Betreff ihrer Entstehung und grossen Zerstörung für den gesammten Apothekerstand als wichlig mir erscheint, und theile ich in dieser Zeilschrift das Nähere nach eigener Besichtigung und Mittheilung des mir befreundeten Collegen, darüber mit.

Gegen 2 Uhr Nachts spürt einer der Nachtwächter des Orts in einer Strasse einen ihm auffallenden Geruch; er verfolgt diesen und kommt zur Apotheke, wo dieser Geruch in weit höherem Grade vorhanden war. . Eine gleich vorgenommene nähere Untersuchung daselbst ergiebt, dass eine nach der Strasse föhrende eiserne Kellerthür ganz heiss ist, Obschon nun durch die in der Thür befindlichen zwei Oeffnungen im Innern des Kellers kein Feuer von dem Wächter bemerkt wird, so macht derselbe doch gleich Allarm zum Herbeirufen der Löschcompagnie. Als hierauf der Apotheken-Besitzer und seine 
Gehülfen herbeieilen, finden sie beim Heraustreten aus dem Schlafzimmer einen bedeutenden Geruch nach brennendem Terpentin oder Terpentinól. Als man an die hölzerne Kellerthür kommt, die aus dem Innern des Hauses in den Keller führt, findet sich diese ebenfalls ganz warm. Ungewiss darüher, ob es geeignet erscheine, die Kellerthür von Innen zu öflnen, lassen sie diese verschlossen, und wird von aussen her, vermittelst der inzwischen herbeigeeilten Brandspritze, Wasser in den Keller gespritzt. Bei dem spätern Eintritt in den Keller durch die Thür von aussen findet sich die furchtbarste Zerstörung. Alle in Keller befindlichen Flaschen und Krüge sind zersprungen, und aile Gefässe, die sämmtlichen Kepositorien und Schrănke, die ganze Decke des starken Gewölbes, so wie die Seitenwände des kurz vorher noch weiss getünchten Kellers nit einem pechschwarzen Russ belegt; diese Schwärzung fand sich auch in mittlern Keller, worin Korbflaschen mit Alkohol, 0l. Terebinth., Ol. Olivar. opt, et ordinar. u. s.w. standen; alles Bretterwerk war auch hier beim Eintritt heiss, und war überhaupt die Hitze im ganzen Souterrain so verbreitel, dass der Wein in den Flaschen des Haushaltungskellers ebenfalls ganz warm war. Ein beim Eingange in den Apothekenkeller rechts befindlicher kleiner Schrank mit ätherischen Oelen war an mehreren Stellen überdies stark angebrannt; überhaupt zeigte sich an diesem Schranke allein ein wirkliches Verbrennen des Holzes zu Kohle; der Schrank war verschlossen, daher sein Inhalt gar nicht zerstört. In dem Keller der Apotheke, der durch eine Absperrung von Tannenlatten von dem übrigen Kellerraume getrennt war, befanden sich an zwei Seiten Repositorien mit sieben Bänken, und waren die verschiedenen Gegenstände ungefăhr wie nachstehend geordnet und aufgestellt.

Es standen auf der ersten obersten Bank des Repositoriums: Syrupe, Alkohol etc.

2te Bank: Die kleinen Tincturen.

3te Bank: Diverse Sachen, Săuren, Aeth. sulphur., Aeth. acet., Lig. ammon. caust. elc.

4te Bank: Die rerschiedenen Aceta, die destillirlen Wässer, Elixir. aur. comp. etc.

5te Bank: Melrosat., Oxymel simpl., Ol. Tereb., Ol. Petrae etc. 6te Bank: Einige Syrupe etc.

Tte Bank: Tincturen.

Nach dem hier Vorgelragenen entsteht nun die Frage: Wie ist das Feuer und die furchtbare Zerstörung entstanden? Es war keiner mit einem Licht Abends im Keller gewesen, bloss der eine Gehülfe des Morgens zum Einfüllen. Die Thüren und Fenster des Kellers waren fest verschlossen, so dass also eine Ansteckung von aussen nicht angenommen werden kann. Der Phosphor stand unversehrt in einer Blechbüchse mit Wasser umgeben unter dem Schranke mit ätherischen Oelen. Der Apothekenbesitzer war gegen Mitternacht noch auf gewesen, indem Verwandte bei demselben zum Besuch waren, und hatte beim Schlafengehen keinen Geruch in Hause bemerkt.

Nach meinem Dafürhalten muss hier eine Selbstentzündung angenommen werden. In der Nähe von Ol. Terebinth., Ol. Pelrae etc., und zwar höher, standen nämlich die stärkern Säuren; vielleicht hat nur eine Katze oder eine Katte ein Gefäss mit starker Säure umgeworfen, es ist das Gefäss mit dem Inhalt auf die darunter stehende Flasche mit $0 l$. Terebinth., $O l$. Petrae etc. gefallen, hat diese theilweise zertrümmert und in Entzündung gebracht, hierdurch sind nun 
die andern brennbaren Stoffe entzundet worden, und hat die grosso Hitze die Zertrümmerung der übrigen Gefãsse veranlasst. Eine bedeutende Erhitzung muss im Anfange des Entstehens statt gefunden haben, wie das wirkliche Verbrennen des Holzes an mehreren Stellen deutlich zeigt; durch die Entstehung eines hỏchst badeutenden Rauches und Dampfes im Keller ist die Flamme selbst wabrscheinlich später erlöscht. - Es scheint mir diese meine ausgesprochen Vermuthung eine wahrscheinliche zu sein; ich w'üsste mir wenigstens eine andere Entstehungsart des Brennens nach allen eingezogenen Erkundigungen nicht zu denken.

Für die Aufstellung der verschiedenen Gegenstãnde der Apotheke giebt uns nun der erwähnte Vorfall einen Fingerzeig, alle starke Säuren isolirt und von allen andern Sachen getrennt aufzubewahren; ich habe mir dazu seit langen Jahren einen eigenen Schrank anfertigen lassen, worin alle rohe und gereinigte Säuren aufbewahrt werden.

Bei dieser Mittheilung richte ich an die rerehrten Collegen die freundliche Bitte, im Fall der Eine oder Andere derselben Erfahrungen über ähnliche Vorfälle gemacht haben sollte, mir diese entweder persönlich, oder durch das Archiv gütigst mittheilen zu wollen.

\section{5) Ueber Verhütung und Heilung der Knotenkrank- heit und Schleimsucht der Blutegel; von Herm. Ha endes s in Sachsa.}

Die Behandlung der Blategel und die Auffindung von Präservativmitteln gegen die Krankheiten derselben sind bereits Gegensland zahlreicher Abhandlungen gewesen, was in der immer noch steigenden Seltenheit und den enorm hohen Preisen der Egel theilweise seinen Grund haben mag.

Unter den zahlreichen in Vorschlag gebrachten Vorbeugungsmilteln gegen die Blutegelkrankheiten finden wir: Kalmus, Torferde, Rasenslücke mit Juncus- und Carex-Arten bewachsen, Kohle, Zucker, Honig etc. Doch genügt keins der eben genannten in dem gewünschten Maasse, ist keins im Stande, die Krankheiten gänzlich und sicher abzuhalten, obgleich sie fast alle antiseptisch wirken.

Unter allen diesen mehr oder minder zweckdienlichen Vorschlägen stehen zwei, erst in neuerer Zeit gemachte, obenan: die Behandlung der Blutegel nit Chlorwasser (cfr. Abhandl, des Hrn. Apoth. Roder in Lenzburg im Journ. für prakt. Pharm. II. 112.) und mit verdünnter Sch wefelsäure (Arch. der Pharm. Jahrg. 1846. Bd. 2. p. 52 u. dess Jahrg. Bd. 3. p. 329). Aufmerksam gemacht durch die eben angezogenen Abhandlungen, brachte ich diese beiden Mittel wälrend aweier Sommer in Anwendung, und hatte die Freude, sie stets yon dem besten Erfolge begleitet zu sehen. Das Chlorwasser wandte ich zu 5 Tropfen auf 36 Unzen weichen Wassers an. Die in diese Mlischung gebrachten Blutegel gerathen in sehr lebhafte Bewegung, und sondern viel bräunlich-grünlichen Schleim ab, welche Erscheinung sich auch bei Behandlung mit verdünnter Schwefelsäure zeigt. Letzlere wird, wie sie sich in der Officin vorfindet, ebenfalls zu 5 Tropfen auf 36 Unzen Wassers wöchentlich höchstens ein Mal in Anwendung gebracht. Durch diese Behandlung der Blutegel mit Schwefelsäure war 